\title{
Innovation Management in European Projects
}

\author{
Bernard Monnier $^{1}$ and Marc Zolghadri ${ }^{2}$ \\ ${ }^{1}$ Monnier Innovation Management, 40, rue Charles de Montesquieu, 92160 Antony, France \\ mim.innovation@ymail.com \\ ${ }^{2}$ IMS - University of Bordeaux, 351, Cours de la Liberation, 33405 Talence, France \\ Marc.Zolghadri@ims-bordeaux. fr
}

\begin{abstract}
Companies need innovation to increase their market share and profit margin. Innovation is the successful product put on the market using a new idea. At the beginning of the process, it is not simple to evaluate if the novelty will be or not an innovation. It is in general after launching and selling the new product that the innovation level can be assessed. This paper addresses one main issue: "How to anticipate the innovation performance for the decision making process?". It suggests a method to measure the innovation level of a product or a service, based on MIM@ (Monnier's Innovation Matrix). This tool could be used for decision making process to support marketing and corporate strategy or a collaborative research project. The added value of this method is that it allows to manage innovation projects. As far as we know, this problem has never been addressed before. The only document, which could be mentioned in this field, is the "Oslo Manual" from European Community. This document is more focused on the innovation issued by technology than services and it concerns large organisation. The MIM tool can also be used as a criterion for advanced partners selection paradigm.
\end{abstract}

Keywords: Innovation, Monnier's Innovation Matrix $\odot$, innovation process, innovation measurement.

\section{Introduction}

Innovation is the successful exploitation of new ideas. Creativity is the production of new ideas. Innovation is about bringing new knowledge and processes into business and/or developing new, high value-added products, processes and services. The main issue is to find a way to evaluate the level of innovation, as soon as possible in New Product Development projects.

There is no definite metrics for innovation. Measures of innovative success vary according to companies and industries. The goal of this paper is to propose a tool which can be used for measuring the innovation level of an existing product and determining the best strategy to improve its level. This point will be discussed hereafter. Authors believe that this measurement can also be used as a high-level selection driver within the advanced partners selection paradigm. The major part of the paper 
will be focused on the first purpose while a short description will be provided at the end of the paper discussing this latter issue.

\section{Innovation Measurement}

The Monnier's Innovation Matrix (C) (MIM@) is a new tool aimed at measuring the level of innovation of an offer (in a general sense, a product and/or a service) or a company. The objective of this study is to suggest a new method for measuring innovation in 7 levels. These levels can be applied to most industrial companies.

The Monnier's Innovation Matrix $@$ tool is mainly composed of a two-dimensional matrix where the " $X$ " axis represents the market level and the " $Y$ " axis the new idea (see Figure 1). The technical level of the products or the relevance of a new service based on this new idea will be evaluated. Several parameters are taken into consideration to assess each axis.

This matrix could be considered as a standard measure for different products or services, similar to a diagnostic framework where analysts may identify some parameters to focus on in order to improve the innovation level. This paper describes how this matrix is built and how to increase the innovation level from one situation "As Is" to another more favorable "To Be".

The performance of this measurement depends on the accuracy of information reported on the axes. The measurement methodology is based on specific questionnaire depending on the application domain and the company. This tool is used for evaluating innovation level of an offer as well as company's innovation capability.

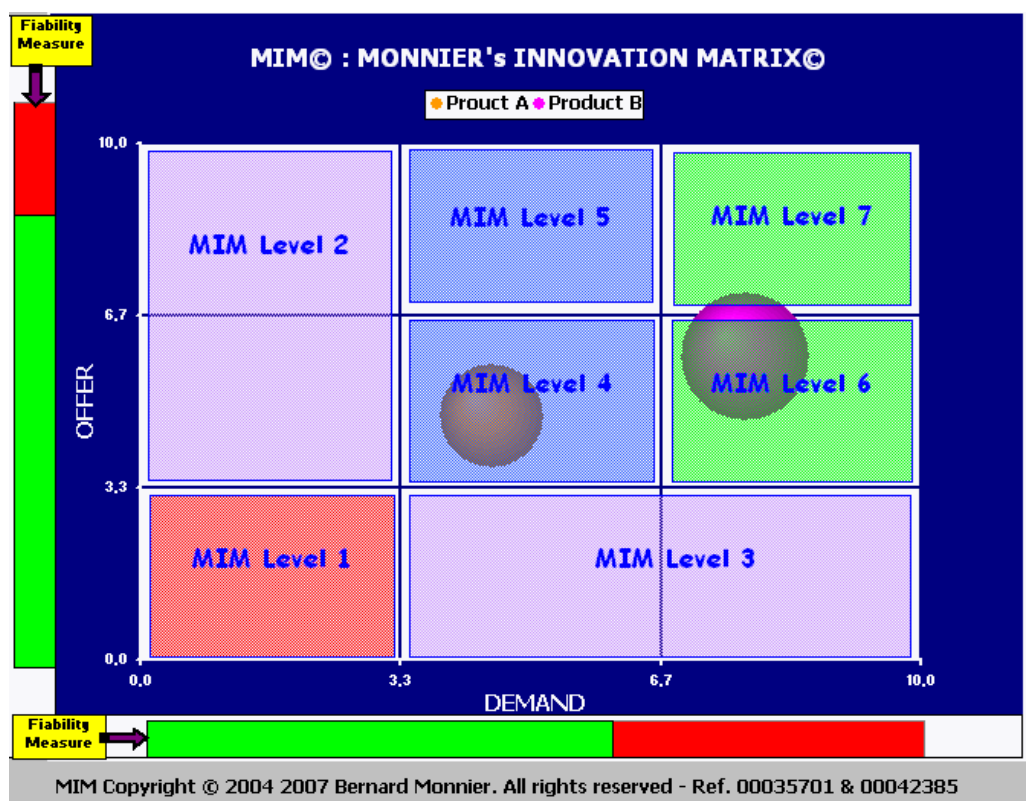

Fig. 1. Monnier's Innovation Matrix@: innovation level for an offer 


\section{The Assessment of Each Axis}

The quality of a measure depends on the definition of the axes. The questions behind the measurement of the market are split into some parameters such as the market, the competitors, the business model defined by the organization for promoting the evaluated offer. Regarding the idea, the offer axis the parameters are: the maturity of the offer, the environment, the protection level (patents) and the respect of the main rules about sustainable development.

\subsection{Market Axis: The Demand}

Market. The market is evaluated in terms of volume, expected returns and growth margin. Innovation is also useful for increasing the market share, therefore the expected level of future growth has also to be considered.

The market parameter has to be modulated by the risks of this market and the reliability of the previous "quotation".

Competitors. This parameter captures the evaluation of the competitors, their number and the level of their competence. We suggest evaluating the difficulties for a new entrant to this market, as well as the level of protection against the new comers. We can also include the evaluation of a really new function or process that consists of differentiating the product from those of the competitors.

Business Model. This parameter is dedicated to the evaluation of the business model efficiency (flexibility, ...).

\subsection{Offer Axis}

Maturity level of the offer. A first set of questions is about the technical solutions: Are they validated enough? What is their reliability? Does the time-to-market is short enough?

Sustainable capability and/or compliance. Sustainable products are those products providing environmental, social and economic benefits while protecting public health, welfare, and environment over their full life cycle, from the extraction of raw materials to final disposition. This parameter evaluates how the product could be considered in accordance with these sustainable development principles.

Technical environment. This parameter is used to evaluate the global context of the problem. Is the solution technically difficult to solve? Is there any knowledge and know-how within the company to manage a potential new problem? The risk level needs to be assessed too in terms of financial, marketing and technical fields. The respect of environmental conditions could be a risk that needs to be considered.

We also have to evaluate if there are method and tools to enhance creativity, to manage knowledge, to measure the level of innovation, and to monitor recommendations.

Protection level. The protection of a technical solution is very important. We need to evaluate if patents protect the solution and if this protection is efficient enough to 
avoid copyright infringement: is it easy to copy and is it easy to detect a copy of the product?

\section{From Measurement to Strategy}

The following stage is dedicated to decide and define a strategy. We propose a dedicated process in four steps that leads to assessment of the degree of innovation of the global supply chain:

- Situation analysis, a shared vision with partners

- Definition of a strategy for each stakeholder

- Implementation of the action plan adopted in accordance with the strategy

- Re-evaluation of the offer innovation

\section{Analysis of the Situation}

We may deduce from the MIM@ referential that the best value is on the $7^{\text {th }}$ level. At this level, the market is at its highest score; that means that a market has been found and the margin is more than expected. If the assessment of the current situation is not yet evaluated to the $7^{\text {th }}$ level, we have to define how to reach this best value of innovation, how to move from initial position to another more favorable quadrant. All partners need to share the same vision of the current position and the expected one. In this case, the contract which is needed to join all the parties, will probably be easier to provide if everyone knows where it starts and where it will want to go, thanks to the partnering driven for innovation.

\section{Defining a Strategy}

A detailed analysis of each criterion on each axis could help to define a strategy for the move. Generally, the only movement we wish to increase is along the market axis; that means to move from the left to the right side. But sometimes, if we expect to reach a high level of market share, we also need to move up from a lower to a higher quadrant. For this reason, methods have been provided for both movements in the matrix each arrow has a cost which needs to be estimated in a strategic "action plan".

\section{Implementation of Methods}

After defining the best strategy, it is necessary to manage the implementation of the method described above.

\section{Re-evaluation of the Modified Product/Service}

During the process and obviously at the end, the product or service should be quite different from the initial one. The modification shall imply a move to a better quadrant (see Figure 2 MIM@ : a strategic tool). The goal of this phase is mainly to confirm that the expected position in the matrix has been reached or in the right way to reach this position at the expected time. (otherwise, the cycle needs to be executed once more). 


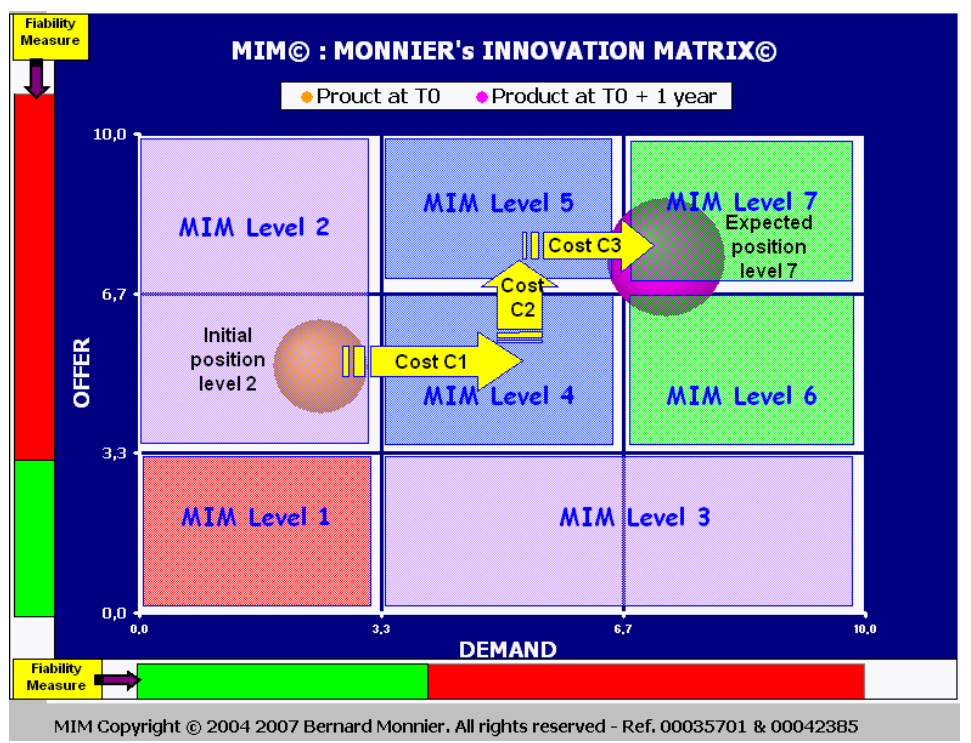

Fig. 2. MIM@ : a strategic tool

\section{Reliability Issues and MIM as a Selection Tool}

The innovation level measurement needs to be reliable. The performance depends on the accuracy of information given for providing the innovation measurement. We need to put trust in the person or the group of people who will assess the parameters on each axis. In order to achieve it, several activities need to be carried out in order to be able to assess with a high level of confidence, all parameters of the axis. The activities are as well as in the technical field or in the marketing domain. The result of this analysis is superposed on the same graph (see Figure 1). The green color indicates the level of trust (percentage) in the innovation measurement process.

Finally, it should be underlined that the measurement of innovation capability of the potential partners can be used a high-level selection criterion. A successful NPD project needs efficient partners. The partners capability allows to ensure projects success or on the contrary to its failure. In order to be able to use this tool for partners selection, we suggest the consideration of most probable scenarios considering major and most important potential partners. The feasibility of such project consortium is measured by auditing experts. Each scenario should show the As Is situation of the product and the effort required by the companies to reach the target, To Be. By comparing these scenarios it is then possible to choose the most relevant partners regarding the project target. In fact each scenario corresponds to a given trajectory in MIM and represents the efforts necessary to go from As Is to To Be situations by considering the partners possibilities. 


\section{Morgan Project: An Example of Program That Drives Our Study}

Some European projects are managing innovation with MIM@ methodology. As an example, the MORGaN project includes a dedicated WP for evaluating innovation. An "Innovation plan" will be provided in addition to the exploitation plan and the dissemination plan, required by all European Projects.

MORGaN project (Materials fOr Robust Gallium Nitride, www.morganproject.eu) addresses the need for a new materials basis for electronics and sensors that operate in extreme conditions, especially high temperature and high electric field. It will take advantage of the excellent physical properties of diamond and gallium nitride (GaN) based heterostructures. The association of the two materials will give rise to better materials and devices for ultimate performance in extreme environments.

This project benefits from the MIM@ tool in order to manage innovation with a great number of different partners (academic institutes, SMEs, Industrial, ...) around "Open Innovation" organization. We also benefit from this use case to drive our study on supply chain management. The questionnaire is dedicated to evaluate the outcomes and the innovation capability of each partner in this project. Such information is essential for managing an innovative supply with different partners in the loop.

This method could gain to be shared by a lot of other organizations in order to improve this methodology and to share the same referential. The more it will be used, the better this tool will become. A new application in a new domain would be appreciated; this paper could be an efficient way to build more case studies.

Finally, the MIM@ referential is a new process dedicated to work in "open innovation". It is dedicated to:

- Evaluate the level of innovation

- Define a strategy to improve innovation

- Decision-making process

- Action plan and continuous improvement monitoring

- Communicate

\section{Conclusion}

Innovation is defined as the successful development and exploitation of a new idea. It is the incentive to increase market share, higher growth rate and greater profitability. Innovation applies to new technologies, products and processes, as well as to the implementation of best practices in industry. MIM@ referential could be efficient to measure innovation and to define a strategy to increase it. The action plan to improve our current position may be followed using the same tool. It could be considered as an efficient collaborative work platform, for the benefits of an open innovation project management.

The applications of innovation level measurement are not restricted to R\&D or Marketing. The multiple application of the MIM(C methodology is one of the reason why this framework seems to be appreciated by a lot of department within a company, for example, purchasing and supply chain management. 
The following list gives some examples of different use of the MIM@ methodology:

- Evaluation of innovation level for an offer (product and/or service),

- Innovation level of a supplier,

- Evaluation of the innovation capability of the main outputs of a research study,

- A strategic tool for decision making about patents,

- A tool for developing a market for a doctoral thesis,

- A framework for managing a collaborative work with multiple partners, academic, SME, industrials,

The MIM(C tool could be seen as an efficient collaborative tool to be fostered in partnership contract with supplier(s). That helps to share a same view of the product or service you work on in team with innovative supplier(s). European projects are interesting cases for evaluating the process of managing a supply chain organization in order to improve innovation.

\section{References}

1. Christensen, Harper Collins edition, The Innovator's Dilemma: The Revolutionary Book That Will Change the Way You Do Business (2003)

2. Christensen, Hardcover edition, The Innovator's Solution: Creating and Sustaining Successful Growth (1997)

3. Kraljic, Harvard Business Review, pp 109-117, Purchasing must become supply management (September-October 1983)

4. Millier, Palmer, Wiley edition, Nuts, Bolts \& Magnetrons: A Practical Guide for Industrial Marketers (2000)

5. Millier, Dunod, Stratégie et Marketing de l'Innovation Technologique (1997)

6. Millier, Edition d'Organisation, L'Etude des Marchés qui n'Existent pas Encore (2002)

7. Monnier, IPSERA International Conference, Archamps, France. A new tool to evaluate supplier's level of innovation (March 20-23, 2005)

8. Monnier, IPSERA International Conference, San Diego, USA. Supplier's Innovation Management by Portfolio Model (April 6-8, 2006)

9. Monnier, TRIZ Future International Conference, Florence, Italy. Application of the TRIZ method to business management activities (November 3-5, 2004)

10. Monnier, SAM International Conference, Las Vegas, USA. A New Process For Innovation Improvement (April 2-5, 2005)

11. Monnier, AMETRIZ International Conference, Puebla, Mexico. Innovation Improvement Strategy Using TRIZ (September 4-7, 2006)

12. Monnier, Josset, SAFE 2007 International Conference, Ramla Bay, Malta, Innovation Measure through the European Project SERKET (June 25-27, 2007)

13. Monnier CIGI, 8ième Congrès international de Génie Industriel, Bagnères de Bigorre, Méthode de mesure de l'Innovation (June 10-12, 2009)

14. Van Weele, Thomson edition: Purchasing and Supply Chain Management, Analysis, Planning and Practice, 3rd edn. (2002)

15. Zouggar, Zolghadri, Girard, CIGI, 8ième Congrès international de Génie Industriel, Bagnères de Bigorre, Une meilleure sélection des partenaires pour une performance optimale (June 10-12, 2009) 